Volume $50 \cdot$ Number I $\cdot 2013$

\title{
VA PROSTHETIC AND SENSORY AIDS SERVICE-65 YEARS OF PROGRESS
}

\section{LUCILLE BECK, PHD, CHIEF CONSULTANT, VETERANS HEALTH ADMINISTRATION PROSTHETIC AND SENSORY AIDS SERVICE}

1 he JRRD article written by Stewart in 1965 entitled "Twenty Years of Progress" highlighted the progress of the Veteran Administration's Prosthetic and Sensory Aids Service since World War II. Recognizing the importance of prosthetic and sensory aids to Veteran healthcare during those early days set the foundation for the department of today to become the largest and most comprehensive provider of prosthetic devices and sensory aids in the world.

Since 1965, the world has experienced unprecedented advancements in technology and healthcare with the development of the personal computer and advent of the "Information Age," the Internet and global communication, and the rapid evolution of microtechnology. The "Veteran Administration" has become the Department of Veterans Affairs (VA), the second largest department in the Federal government, employing more than 280,000 employees and operating America's largest integrated healthcare system, with more than 1,700 hospitals, clinics, community living centers, domiciliaries, readjustment counseling centers, and other facilities. In fiscal year 2012, VA surpassed the level of prosthetic and sensory aids services provided in previous years, spending more than $\$ 2$ billion to provide 14.5 million prosthetic devices, items, sensory aids, and services to more than 2.7 million Veterans. Nearly half of all Veterans currently seen in VA for healthcare receive prosthetic and sensory aids services and nearly onethird see a rehabilitation services healthcare provider.

In the half century since publication of Stewart's article, our nation has also been engaged in military conflicts in Vietnam, Persian Gulf, Africa, Bosnia, Kosovo, Iraq, and Afghanistan. Military medical and tactical advancements have resulted in a significant increase in the survivability of combat-related injuries in Iraq and Afghanistan. As we strive to meet VA's core mission of serving and honoring America's Veterans, we recognize that the goal of VA's Rehabilitation and Prosthetic and Sensory Aids Services remains steadfast: to maximize Veterans' independence and maintain an optimal level of physical and cognitive function that enables them to integrate successfully into their communities.

The way in which VA helps Veterans successfully achieve this goal in 2013 is through a patient-centered interdisciplinary care team in a fully engaged partnership with Veterans and their families. Today, VA provides the full spectrum of world-class prosthetic and rehabilitation services for Veterans-whether such services are needed as a result of ordinary healthrelated changes or more complex and multiple injuries (i.e., polytrauma), including traumatic amputation, traumatic brain injury, spinal cord injuries and disorders, vision impairment and blindness, hearing loss, and musculoskeletal injuries.

Using interdisciplinary healthcare teams and advanced systems of care to deliver rehabilitation and prosthetic services, VA provides all clinically appropriate and commercially available state-of-the-art prosthetic equipment and sensory aids and devices that cross the full range of patient care. Such items include artificial limbs and bracing, wheeled mobility and seating systems, sensory-neural aids (e.g., hearing aids, eyeglasses), cognitive prosthetic devices, items specific to women's health, surgical implants, home respiratory care, recreational and sports equipment, and special benefits programs (to include clothing allowance, automobile adaptive equipment, and home improvement and structural alterations).

VA meets the rehabilitation and prosthetic needs of Veterans in the 21st century by engaging in a dynamic process that (1) conducts and supports research to develop new technologies and clinical practices; (2) evaluates and integrates emerging products and technologies; (3) applies an evidence-based synthesis approach to assess outcomes-driven care and services; and (4) coordinates clinical 
xviii

JRRD, Volume 50, Number 1 , 2013

practice recommendations with contracting requirements in order to improve effectiveness and efficiency, while advancing future technologies and clinical systems of care. To ensure that this process is integrated and comprehensive, VA collaborates with many strategic partners, includ- ing the Department of Defense, the academic and professional communities, and, most importantly, Veterans and their families.

As we face the exciting challenge of advancing the development and use of new technologies for the nation's Veterans, VA rehabilitation and prosthetic services will continue its mission to adapt and transform the delivery of services and devices that improve function and independence for Veterans. 